\title{
Comparison of anterior corpectomy and fusion versus laminoplasty for the treatment of cervical ossification of posterior longitudinal ligament: a meta-analysis
}

\author{
Zihao Chen, MD, Bin Liu, MD, Jianwen Dong, MD, Feng Feng, MD, Ruiqiang Chen, MD, \\ Peigen Xie, MD, Liangming Zhang, MD, and Limin Rong, MD \\ Department of Spine Surgery, The Third Affiliated Hospital of Sun Yat-sen University, Guangzhou, China
}

\begin{abstract}
OBJECTIVE The purpose of this study was to compare the effectiveness and safety of anterior corpectomy and fusion (ACF) with laminoplasty for the treatment of patients diagnosed with cervical ossification of the posterior longitudinal ligament (OPLL).

METHODS The authors searched electronic databases for relevant studies that compared the use of ACF with laminoplasty for the treatment of patients with OPLL. Data extraction and quality assessment were conducted, and statistical software was used for data analysis. The random effects model was used if there was heterogeneity between studies; otherwise, the fixed effects model was used.
\end{abstract}

RESULTS A total of 10 nonrandomized controlled studies involving 819 patients were included. Postoperative Japanese Orthopaedic Association (JOA) score ( $p=0.02,95 \% \mathrm{Cl} 0.30-2.81$ ) was better in the ACF group than in the laminoplasty group. The recovery rate was superior in the ACF group for patients with an occupying ratio of OPLL of $\geq 60 \%$ $(p<0.00001,95 \% \mathrm{Cl} 21.27-34.44)$ and for patients with kyphotic alignment $(p<0.00001,95 \% \mathrm{Cl} 16.49-27.17)$. Data analysis also showed that the ACF group was associated with a higher incidence of complications $(p=0.02,95 \% \mathrm{Cl}$ $1.08-2.59)$ and reoperations $(p=0.002,95 \% \mathrm{Cl} 1.83-14.79)$, longer operation time $(p=0.01,95 \% \mathrm{Cl} 17.72-160.75)$, and more blood loss ( $\mathrm{p}=0.0004,95 \% \mathrm{Cl} 42.22-148.45)$.

CONCLUSIONS For patients with an occupying ratio $\geq 60 \%$ or with kyphotic cervical alignment, ACF appears to be the preferable treatment method. Nevertheless, laminoplasty seems to be effective and safe enough for patients with an occupying ratio $<60 \%$ or with adequate cervical lordosis. However, it must be emphasized that a surgical strategy should be made based on the individual patient. Further randomized controlled trials comparing the use of ACF with laminoplasty for the treatment of OPLL should be performed to make a more convincing conclusion.

http://thejns.org/doi/abs/10.3171/2016.3.FOCUS15596

KEY WORDS anterior corpectomy and fusion; laminoplasty; cervical; ossification of posterior longitudinal ligament; meta-analysis

$\mathrm{O}$ SSIFICATION of the posterior longitudinal ligament (OPLL) is a common cause of cervical compressive myelopathy. The incidence of OPLL in Asian countries is estimated to range from $0.4 \%$ to $3.0 \%$, while the incidence ranges from $0.1 \%$ to $1.7 \%$ among North Americans and Europeans. ${ }^{1,23}$ Surgical treatment should be performed in patients with moderate or severe symp- tomatic myelopathy who exhibit significant compression on MRI or CT myelography. Prophylactic surgery is usually recommended in asymptomatic patients who have severe cord compression and demonstrate increased signal on T2-weighted MRI of the cervical cord. ${ }^{6}$ Surgical decompression can be performed via an anterior, a posterior, or a combined anteroposterior approach.

ABBREVIATIONS ACF = anterior corpectomy and fusion; $\mathrm{Cl}=$ confidence interval; $\mathrm{CSF}=$ cerebrospinal fluid; JOA = Japanese Orthopaedic Association; NOS = Newcastle-Ottawa Scale; OPLL = posterior longitudinal ligament; $\mathrm{OR}=$ odds ratio; $\mathrm{WMD}=$ weighted mean difference.

SUBMITTED November 8, 2015. ACCEPTED March 17, 2016.

INCLUDE WHEN CITING DOI: 10.3171/2016.3.FOCUS15596. 
Anterior corpectomy and fusion (ACF) and posterior laminoplasty are 2 traditional surgical procedures that are widely used for treating patients with OPLL. The ACF procedure is used to achieve direct decompression by resection of the ossified mass via an anterior approach. The advantages of the anterior approach are as follows: 1) removal of the ossified mass enables complete decompression, and 2) spinal fusion can stabilize the cervical spine and relieve pressure on the injured cord. However, the following disadvantages are also notable: 1) the operation is more technically demanding, 2) a bone graft harvested from the iliac or fibula may be needed, 3) a longer postoperative immobilization period is required, and 4) the incidence of complications is high. ${ }^{1,5,16,20,22}$

Laminoplasty expands the available space of the spinal canal so as to achieve indirect decompression by shifting the spinal cord posteriorly. The relative advantages of laminoplasty are as follows: 1) the technique is easy to grasp, and 2) a shorter postoperative immobilization period is required. The disadvantages of laminoplasty include the following: 1) indirect decompression may lead to poor outcomes, especially for highly occupied OPLL; 2) adequate cervical lordosis is required for a satisfactory outcome; 3 ) postoperative cervical instability and kyphosis may lead to neurological deterioration; and 4) postoperative nuchal pain is frequent. $15,20,22,26$

Although many studies in recent years have compared the outcomes of patients treated using ACF with the outcomes of those treated using laminoplasty, all were nonrandomized controlled studies with poor quality and conflicting results. Given these previous studies, the optimal surgical approach for the treatment of patients with OPLL remains controversial. We believe that there are differences between ACF and other anterior procedures; likewise, laminoplasty is also different from other procedures that use a posterior approach. We strategized that specifically focusing on the narrow topic of ACF and laminoplasty may lower the potential clinical heterogeneity. Therefore, we performed a meta-analysis of recent studies to compare the use of $\mathrm{ACF}$ with that of laminoplasty for patients with OPLL in terms of neurological outcomes, complications, reoperations, and surgical trauma.

\section{Methods}

\section{Inclusion and Exclusion Criteria}

Studies were included in our meta-analysis if they met the following inclusion criteria: 1) they were randomized or nonrandomized controlled studies, 2) patients were diagnosed with cervical OPLL, 3) comparative data between ACF and laminoplasty were available, 4) sample size was bigger than 10, and 5) follow-up time was longer than 1 year.

Studies were excluded according to the following exclusion criteria: 1) patients had cervical myelopathy caused by trauma, tumor, or infection; 2) patients had previous cervical surgery; and 3) patients had undergone decompression by a combined anteroposterior approach.

\section{Search Strategies}

A computerized search was conducted on the PubMed,
Scopus, and Cochrane Library electronic databases. The following search terms were used: "anterior," "ventral," "corpectomy," "posterior," "dorsal," "laminoplasty," "cervical," "ossified," "ossification," and "posterior longitudinal ligament," with combinations of the Boolean operators "AND" and "OR." Studies were limited to those published between January 1990 and September 2015. References within relevant review articles were checked to identify additional underlying studies.

\section{Data Extraction}

Two investigators independently extracted data from included studies. Disagreements were solved by discussion. The following data were extracted: demographic information, clinical outcomes (preoperative and postoperative Japanese Orthopaedic Association [JOA] score, recovery rate), radiological outcomes, incidence of complications and reoperations, operation time, and intraoperative blood loss. The extracted data were rechecked to ensure accuracy.

\section{Quality Assessment}

The quality of all included studies was assessed using the Newcastle-Ottawa Scale (NOS). ${ }^{29}$ The NOS is recommended by the Cochrane Handbooks version 5.10 to assess the risk of bias in nonrandomized studies. The NOS uses a "star system" (maximum of 9 stars) to evaluate 3 broad perspectives: the selection of study groups; the comparability of study groups; and the ascertainment of either the exposure or the outcome of interest for case-control or cohort studies, respectively. Two investigators assessed the quality of the studies.

\section{Data Analysis}

Review Manager software (RevMan 5.3, The Cochrane Collaboration) was used to conduct the statistical analysis. Continuous variables were reported as the weighted mean difference (WMD) and 95\% confidence interval (95\% CI), while dichotomous variables were reported as the odds ratio (OR) and 95\% CI. The random effects model was used if there was heterogeneity $\left(\mathrm{I}^{2} \geq 50 \%\right.$ in a heterogeneity test) between studies; otherwise, the fixed effects model was used $\left(\mathrm{I}^{2}<50 \%\right.$ in a heterogeneity test). For data that are presented as medians and ranges, the value of means and standard deviations were calculated using the formula described by Hozo et al. ${ }^{11}$ Collected data were entered into a computer, rechecked, and analyzed by 2 investigators.

\section{Results \\ Search Results}

A total of 716 studies were obtained from the literature searches. According to our inclusion and exclusion criteria, 10 articles were finally selected into our meta-analysis, including 1 prospective nonrandomized study ${ }^{27}$ and 9 retrospective studies (Fig. 1). 2,3,8,16,18,19,21,22,28 The basic characteristics of included studies are shown in Table 1. No statistically significant differences were found in age, sex, occupying ratio of OPLL, and follow-up time between the 2 groups. 


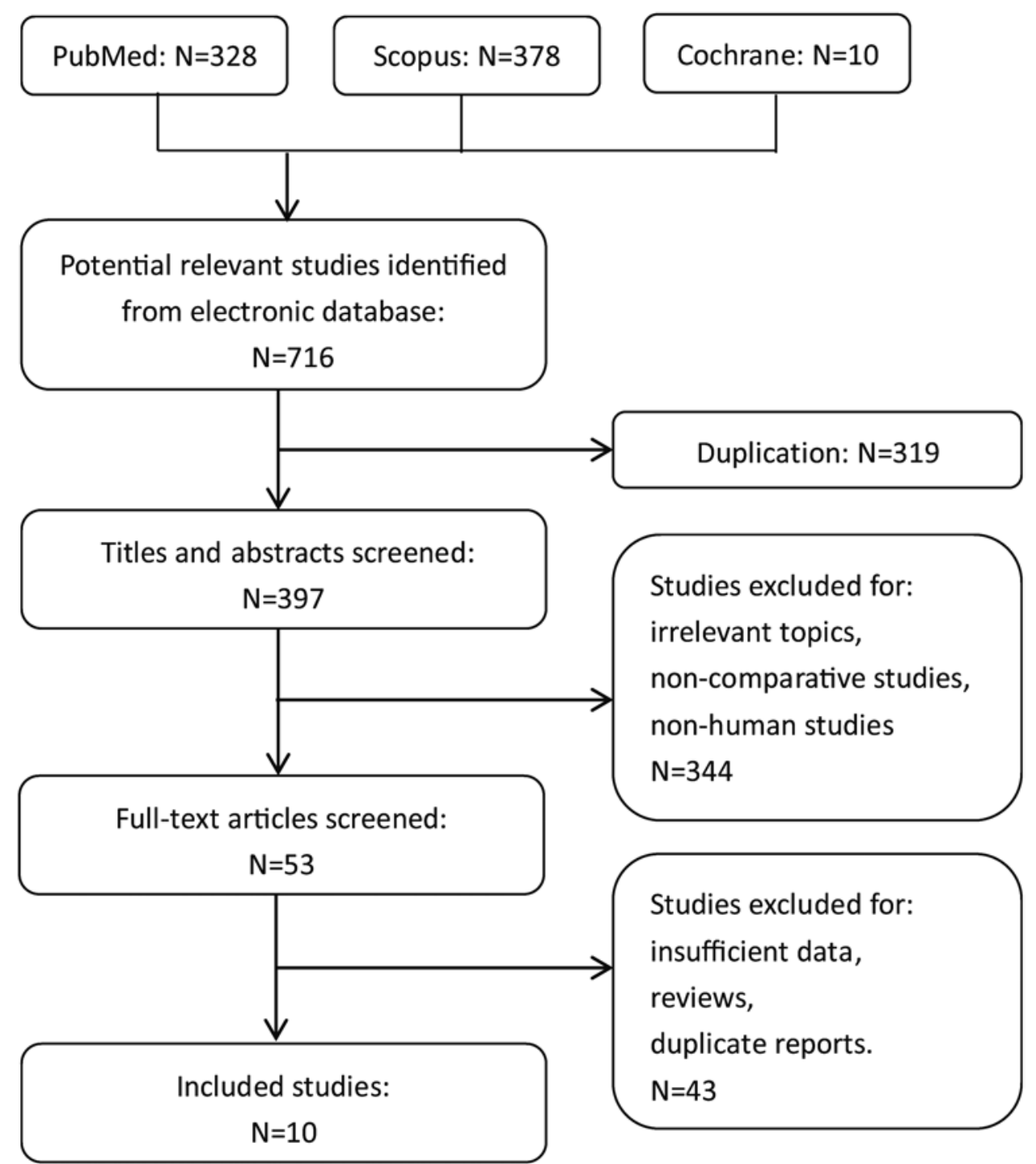

FIG. 1. Flow diagram for study selection.

\section{Quality Assessment}

Quality assessment of the included studies was independently conducted by 2 investigators, and arguments were resolved by discussion. Of the 10 nonrandomized controlled studies, $9^{2,3,8,16,19,21,22,27,28}$ received more than 7 stars on the NOS and the 1 remaining study ${ }^{18}$ received 6 stars. These ratings meant that all included studies were of relatively high quality. The quality assessment is summarized in Table 2 .

\section{Clinical Outcomes}

Preoperative JOA scores were available from 9 studies. . $3,8,16,18,21,22,27,28$ No statistical difference was found between the $\mathrm{ACF}$ group and the laminoplasty group ( $\mathrm{p}=$ 0.85 , WMD $0.04,95 \%$ CI -0.36 to 0.43 ; Fig. 2). Four studies $^{3,22,27,28}$ provided the means and standard deviations for the number of involved segments for each group. It is not surprising that laminoplasty was used for patients with a greater number of involved segments $(\mathrm{p}<0.0001$, WMD $-1.4,95 \% \mathrm{CI}-1.47$ to -1.32 ; Table 1$)$.
Postoperative JOA scores were extracted from 8 stud-

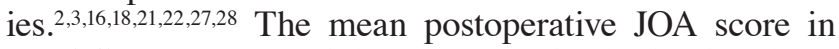
the ACF group was higher than that in the laminoplasty group, with high heterogeneity for the comparison ( $\mathrm{p}=$ 0.02 , WMD 1.55, 95\% CI 0.30-2.81; $\mathrm{I}^{2}=95 \%$; Fig. 3). Hence, the random effects model was chosen for analysis.

Recovery rate data were available from 9 studies. ${ }^{2,3,8,16 \text {, }}$ $18,21,22,27,28$ Similar to the aforementioned result, the mean recovery rate was significantly higher in the ACF group $\left(\mathrm{p}=0.001, \mathrm{WMD} 18.28,95 \%\right.$ CI 7.02-29.54; $\mathrm{I}^{2}=95 \%$; Fig. 4).

In 4 studies, $3,16,18,21$ patients were divided into 2 subgroups based on the occupying ratio of OPLL: mild subgroup (occupying ratio $<60 \%$ ) and severe subgroup (occupying ratio $\geq 60 \%$ ). The occupying ratio was defined as the ratio of the maximum anteroposterior thickness of OPLL to the anteroposterior diameter of the bony cervical canal at the corresponding level on a lateral radiograph or axial CT scan. Among patients with an occupying ratio < $60 \%$, no statistical difference was found for the postoper- 
TABLE 1. Basic characteristics of included studies

\begin{tabular}{|c|c|c|c|c|c|c|c|c|c|c|}
\hline $\begin{array}{c}\text { Authors \& } \\
\text { Year }\end{array}$ & Study Type & Country & Group & $\begin{array}{l}\text { Sample } \\
\text { Size }\end{array}$ & $\begin{array}{l}\text { Mean Age in Yrs } \\
\pm S D \text { or (range) }\end{array}$ & $\begin{array}{l}\operatorname{Sex} \\
(M / F)\end{array}$ & $\begin{array}{c}\text { No. of } \\
\text { Segments* }\end{array}$ & $\begin{array}{l}\text { Surgical } \\
\text { Approach }\end{array}$ & Follow-Up & Pre-JOA \\
\hline \multirow{2}{*}{$\begin{array}{l}\text { Chen et al., } \\
2011\end{array}$} & \multirow{2}{*}{$\begin{array}{l}\text { Retrospec- } \\
\text { tive }\end{array}$} & \multirow[t]{2}{*}{ China } & ACF & 22 & $57.2(43-71)$ & $14 / 8$ & $\geq 3$ & ACF & $\geq 48$ & $9.3 \pm 1.8$ \\
\hline & & & LAM & 25 & $54.2(32-66)$ & $16 / 9$ & $\geq 3$ & OD or FD LAM & $\geq 48$ & $8.5 \pm 0.7$ \\
\hline \multirow{2}{*}{$\begin{array}{l}\text { Chen et al., } \\
2012\end{array}$} & \multirow{2}{*}{$\begin{array}{l}\text { Retrospec- } \\
\text { tive }\end{array}$} & \multirow[t]{2}{*}{ China } & ACF & 94 & $48.7 \pm 1.4$ & $63 / 28$ & $2.7 \pm 0.2^{*}$ & ACF & $48-72$ & $9.8 \pm 0.2$ \\
\hline & & & LAM & 41 & $46.3 \pm 2.5$ & $33 / 8$ & $4.1 \pm 0.2$ & LAM & $48-72$ & $10.2 \pm 0.3$ \\
\hline \multirow{2}{*}{$\begin{array}{l}\text { Goto \& Kita, } \\
\quad 1995\end{array}$} & \multirow{2}{*}{$\begin{array}{l}\text { Retrospec- } \\
\text { tive }\end{array}$} & \multirow[t]{2}{*}{ Japan } & ACF & 34 & NA & NA & NA & ACF & $\geq 24$ & $7.8 \pm 3.2$ \\
\hline & & & LAM & 65 & NA & NA & NA & OD LAM & $\geq 24$ & $7.6 \pm 2.9$ \\
\hline \multirow{2}{*}{$\begin{array}{l}\text { Iwasaki et al., } \\
2007^{16}\end{array}$} & \multirow{2}{*}{$\begin{array}{l}\text { Retrospec- } \\
\text { tive }\end{array}$} & \multirow[t]{2}{*}{ Japan } & ACF & 27 & $58(41-74)$ & $15 / 12$ & $\geq 2$ & ACF & $72(24-240)$ & $9.5 \pm 2.4$ \\
\hline & & & LAM & 66 & $57(41-75)$ & $51 / 15$ & $\geq 2$ & OD LAM & $122.4(60-240)$ & $9.2 \pm 3.8$ \\
\hline \multirow{2}{*}{$\begin{array}{l}\text { Kim et al., } \\
2015\end{array}$} & \multirow{2}{*}{$\begin{array}{l}\text { Retrospec- } \\
\text { tive }\end{array}$} & \multirow[t]{2}{*}{ Korea } & ACF & 71 & $57.3(35-76)$ & $51 / 20$ & NA & $\mathrm{ACF}$ & $48(12-68)$ & $12 \pm 2.7$ \\
\hline & & & LAM & 64 & $56.4(35-76)$ & $49 / 15$ & NA & OD LAM & $41(24-64)$ & $12 \pm 3$ \\
\hline \multirow{2}{*}{$\begin{array}{l}\text { Lee et al., } \\
2008\end{array}$} & \multirow{2}{*}{$\begin{array}{l}\text { Retrospec- } \\
\text { tive }\end{array}$} & \multirow[t]{2}{*}{ Korea } & ACF & 20 & $56.8(42-72)$ & $15 / 5$ & $\geq 3$ & Laser-assisted ACF & $21.8(6-61)$ & NA \\
\hline & & & LAM & 27 & $54.7(30-70)$ & $26 / 1$ & $\geq 3$ & OD LAM & $29.1(11-64)$ & NA \\
\hline \multirow{2}{*}{$\begin{array}{l}\text { Liu et al., } \\
2013\end{array}$} & \multirow{2}{*}{$\begin{array}{l}\text { Retrospec- } \\
\text { tive }\end{array}$} & \multirow[t]{2}{*}{ China } & ACF & 68 & $54.4 \pm 12.8$ & $36 / 32$ & NA & ACF & $\geq 60$ & $7.6 \pm 2.5$ \\
\hline & & & LAM & 59 & $57.9 \pm 9.5$ & $25 / 34$ & NA & FD LAM & $\geq 60$ & $7.7 \pm 2.7$ \\
\hline \multirow{2}{*}{$\begin{array}{l}\text { Masaki et al., } \\
2007\end{array}$} & \multirow{2}{*}{$\begin{array}{l}\text { Retrospec- } \\
\text { tive }\end{array}$} & \multirow[t]{2}{*}{ Japan } & ACF & 19 & $51.8 \pm 6.6$ & $14 / 5$ & $2.5 \pm 1.1^{*}$ & ACF & $\geq 12$ & $8.3 \pm 2.9$ \\
\hline & & & LAM & 40 & $62.6 \pm 10.3$ & $30 / 10$ & $4.1 \pm 1.3$ & OD LAM & $\geq 12$ & $8.6 \pm 2.4$ \\
\hline \multirow{2}{*}{$\begin{array}{l}\text { Sakai et al., } \\
2012\end{array}$} & \multirow{2}{*}{$\begin{array}{l}\text { Prospec- } \\
\text { tive }\end{array}$} & \multirow[t]{2}{*}{ Japan } & ACF & 22 & $59.5 \pm 9.3$ & NA & $3.1(1-5)^{*}$ & ACF & $\geq 60$ & $14.4 \pm 2.8$ \\
\hline & & & LAM & 29 & $58.4 \pm 9.6$ & NA & $4.5(4-5)$ & FD LAM & $\geq 60$ & $10.9 \pm 2.3$ \\
\hline \multirow{2}{*}{$\begin{array}{l}\text { Tani et al., } \\
2002\end{array}$} & \multirow{2}{*}{$\begin{array}{l}\text { Retrospec- } \\
\text { tive }\end{array}$} & \multirow[t]{2}{*}{ Japan } & ACF & 14 & $62 \pm 11$ & $11 / 3$ & $3.5 \pm 1$ & Microsurgical ACF & $49 \pm 34$ & $9.4 \pm 2.5$ \\
\hline & & & LAM & 12 & $66 \pm 6$ & $9 / 3$ & $4 \pm 1.2$ & OD or FD LAM & $50 \pm 43$ & $8.8 \pm 2.8$ \\
\hline
\end{tabular}

$\mathrm{FD}=$ French door; $\mathrm{LAM}=$ laminoplasty; $\mathrm{NA}=$ not available; $\mathrm{OD}=$ open door; Pre-JOA = preoperative $\mathrm{JOA}$ score.

* Statistically significant difference.

ative recovery rate between the 2 groups $(\mathrm{p}=0.53$, WMD $4.48,95 \%$ CI -9.47 to $18.43 ; \mathrm{I}^{2}=96 \%$ ). However, among patients with an occupying ratio $\geq 60 \%$, data analysis showed a significant difference in the recovery rate that favored the ACF group ( $\mathrm{p}<0.00001$, WMD 27.85, 95\% CI 21.27-34.44; $\mathrm{I}^{2}=83 \%$; Fig. 5).

\section{Results Related to Radiological Assessment}

Data associated with radiological outcomes were rarely available in the included studies. The number of patients with preoperative and postoperative kyphosis and the angle of postoperative cervical lordosis are shown in Table 3 .

Meanwhile, the recovery rate of kyphotic patients and

TABLE 2. Quality assessment according to the NOS

\begin{tabular}{lcccc}
\hline \multicolumn{1}{c}{ Study } & Selection & Comparability & Outcome & Total \\
\hline Chen et al., 2011 & 3 & 1 & 3 & 7 \\
\hline Chen et al., 2012 & 3 & 1 & 3 & 8 \\
\hline Goto \& Kita, 1995 & 4 & 1 & 3 & 8 \\
\hline Iwasaki et al., 2007 & 3 & 1 & 3 & 7 \\
\hline Kim et al., 2015 & 3 & 1 & 2 & 6 \\
\hline Lee et al., 2008 & 3 & 1 & 3 & 7 \\
\hline Liu et al., 2013 & 4 & 1 & 3 & 8 \\
\hline Masaki et al., 2007 & 3 & 2 & 2 & 7 \\
\hline Sakai et al., 2012 & 4 & 2 & 3 & 9 \\
\hline Tani et al., 2002 & 3 & 1 & 3 & 7 \\
\hline
\end{tabular}

patients with high signal on T2-weighted MRI of the spinal cord are also presented in Table 3. Better recovery rates were observed in the ACF group for patients with preoperative cervical kyphosis ( $\mathrm{p}<0.00001, \mathrm{WMD} 21.83,95 \%$ CI 16.49-27.17; $\mathrm{I}^{2}=0 \%$ ) and high signal on T2-weighted imaging of the cervical cord $(\mathrm{p}<0.0001$, WMD 19.03, 95\% CI 10.35-27.71; $\mathrm{I}^{2}=0 \%$; Fig. 6).

\section{Complications and Reoperations}

Data on complication rates were available for 7 studies. ${ }^{2,3,16,19,21,27,28}$ According to analysis using the fixed effects model, a higher complication rate was found in the ACF group ( $p=0.02$, OR 1.67, 95\% CI 1.08-2.59; Fig. 7). Heterogeneity between studies was low $\left(\mathrm{I}^{2}=23 \%\right)$. The total complication rate from all included studies was $24.85 \%$ in the ACF group and $18.53 \%$ in the laminoplasty group. Dysphagia and hoarseness, cerebrospinal fluid (CSF) leakage, and implant complications were relatively common in the ACF group. Nevertheless, axial pain and C-5 palsy occurred more frequently in the laminoplasty group. Details of complications are shown in Table 4.

There were 5 studies ${ }^{2,16,19,27,28}$ that presented data on reoperations. The ACF group had a statistically higher reoperation rate than the laminoplasty group $(\mathrm{p}=0.002$, OR 5.21, 95\% CI 1.83-14.79; $\mathrm{I}^{2}=35 \%$; Fig. 8).

\section{Operation Time and Blood Loss}

Three studies ${ }^{16,21,27}$ reported data on operation time and intraoperative blood loss. Compared with the laminoplas- 


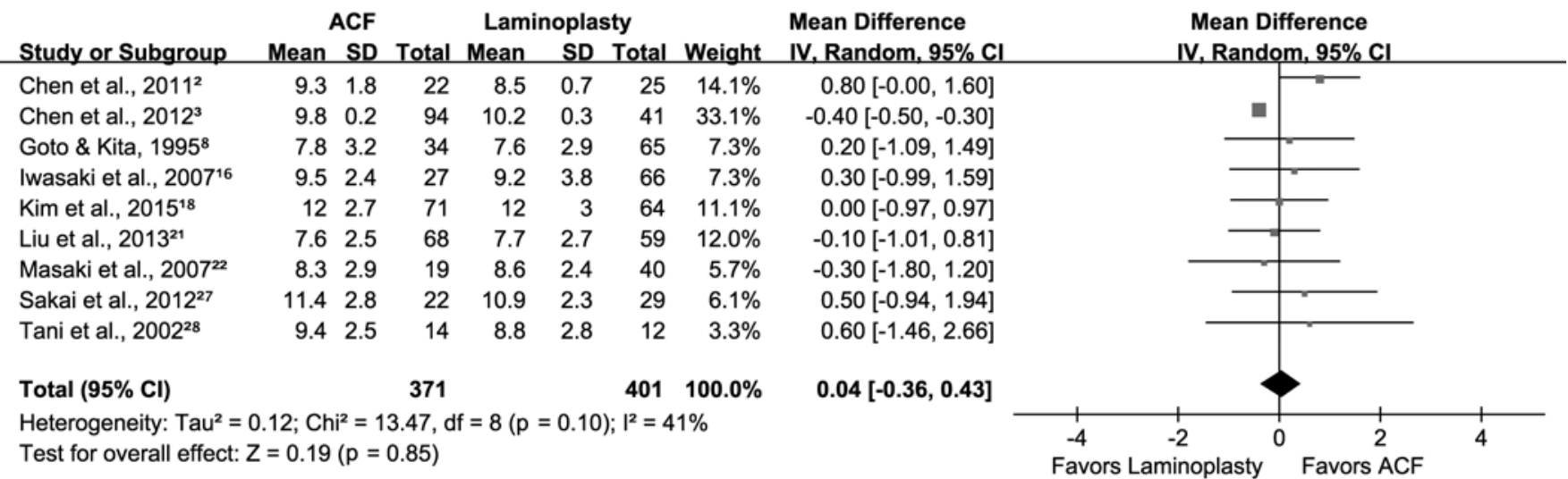

FIG. 2. Forest plot of preoperative JOA scores for the ACF group and the laminoplasty group. IV = inverse variance.

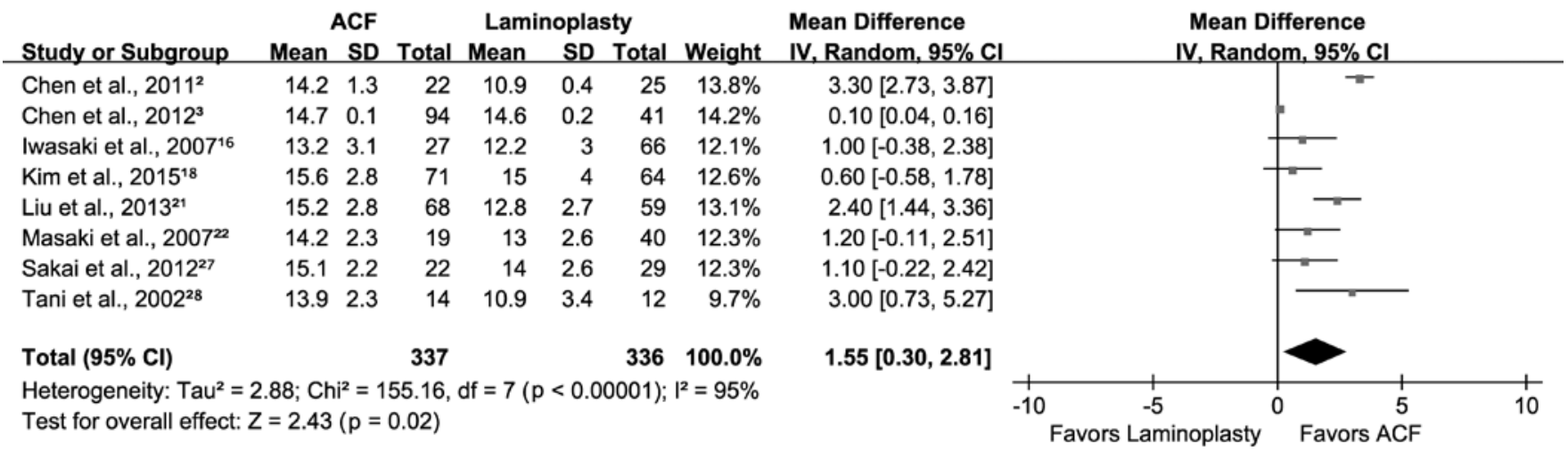

FIG. 3. Forest plot of postoperative JOA scores for the ACF group and the laminoplasty group.

\begin{tabular}{|c|c|c|c|c|c|c|c|c|c|c|c|}
\hline \multirow[b]{2}{*}{ Study or Subgroup } & \multicolumn{2}{|c|}{ ACF } & \multicolumn{4}{|c|}{ Laminoplasty } & & \multirow{2}{*}{$\begin{array}{l}\text { Mean Difference } \\
\text { IV, Random, } 95 \% \mathrm{Cl}\end{array}$} & \multirow{2}{*}{\multicolumn{3}{|c|}{$\begin{array}{c}\text { Mean Difference } \\
\text { IV, Random, } 95 \% \mathrm{Cl}\end{array}$}} \\
\hline & Mean & SD & Total & Mean & SD & Total & Weight & & & & \\
\hline Chen et al., $2011^{2}$ & 63.2 & 15.2 & 22 & 25.1 & 8.5 & 25 & $12.4 \%$ & $38.10[30.93,45.27]$ & & $=$ & \\
\hline Chen et al., $2012^{3}$ & 68 & 2.7 & 94 & 65.2 & 5.8 & 41 & $13.0 \%$ & $2.80[0.94,4.66]$ & & 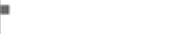 & \\
\hline Goto \& Kita, $1995^{8}$ & 66.2 & 22.8 & 34 & 52.8 & 29 & 65 & $11.7 \%$ & $13.40[2.99,23.81]$ & & & \\
\hline Iwasaki et al., $2007^{16}$ & 51 & 23 & 27 & 55 & 30.3 & 66 & $11.5 \%$ & $-4.00[-15.34,7.34]$ & & & \\
\hline Kim et al., $2015^{18}$ & 72.6 & 38.2 & 71 & 51.9 & 66.3 & 64 & $9.6 \%$ & $20.70[2.19,39.21]$ & & & \\
\hline Liu et al., $2013^{21}$ & 80.6 & 9.7 & 68 & 55.7 & 13.9 & 59 & $12.8 \%$ & $24.90[20.67,29.13]$ & & $=$ & \\
\hline Masaki et al., $2007^{22}$ & 68.4 & 27.3 & 19 & 52.5 & 30 & 40 & $10.5 \%$ & $15.90[0.50,31.30]$ & & & \\
\hline Sakai et al., $2012^{27}$ & 71.4 & 26 & 22 & 55.3 & 29.6 & 29 & $10.5 \%$ & $16.10[0.80,31.40]$ & & & \\
\hline Tani et al., $2002^{28}$ & 58 & 24 & 14 & 13 & 39 & 12 & $7.8 \%$ & $45.00[19.60,70.40]$ & & & \\
\hline Total $(95 \% \mathrm{Cl})$ & & & 371 & & & 401 & $100.0 \%$ & $18.28[7.02,29.54]$ & & & \\
\hline $\begin{array}{l}\text { Heterogeneity: } \mathrm{Tau}^{2}= \\
\text { Test for overall effect: }\end{array}$ & $\begin{array}{l}52.97 ; \\
=3.18\end{array}$ & $\begin{array}{l}C h i^{2}= \\
(p=0 .\end{array}$ & $\begin{array}{l}\text { 176.26, } \\
001)\end{array}$ & $\mathrm{df}=8($ & $p<0$. & $0001) ;$ & $; 1^{2}=95 \%$ & & $\begin{array}{lcc}-100 & -50 & 0 \\
\text { Favors Laminoplasty }\end{array}$ & $\begin{array}{c}50 \\
\text { Favors ACF }\end{array}$ & 100 \\
\hline
\end{tabular}

FIG. 4. Forest plot of recovery rate for the ACF group and the laminoplasty group.

ty group, the ACF group was associated with a longer operation time and more intraoperative blood loss $(\mathrm{p}=0.01$, WMD $89.2495 \%$ CI 17.72-160.75, $\mathrm{I}^{2}=95 \%$ for operation time and $\mathrm{p}=0.0004, \mathrm{WMD} 95.33,95 \%$ CI 42.22-148.45, $\mathrm{I}^{2}=49 \%$ for intraoperative blood loss; Fig. 9).

\section{Discussion}

This meta-analysis of 1 prospective nonrandomized study and 9 retrospective studies (819 total patients) comparing ACF with laminoplasty showed that ACF treatment resulted in better neurological recovery for patients with OPLL, especially those with an occupying ratio $\geq$ $60 \%$ and kyphotic cervical alignment. However, the ACF procedure was associated with a higher incidence of complications and revisions, longer operation time, and more intraoperative blood loss. 


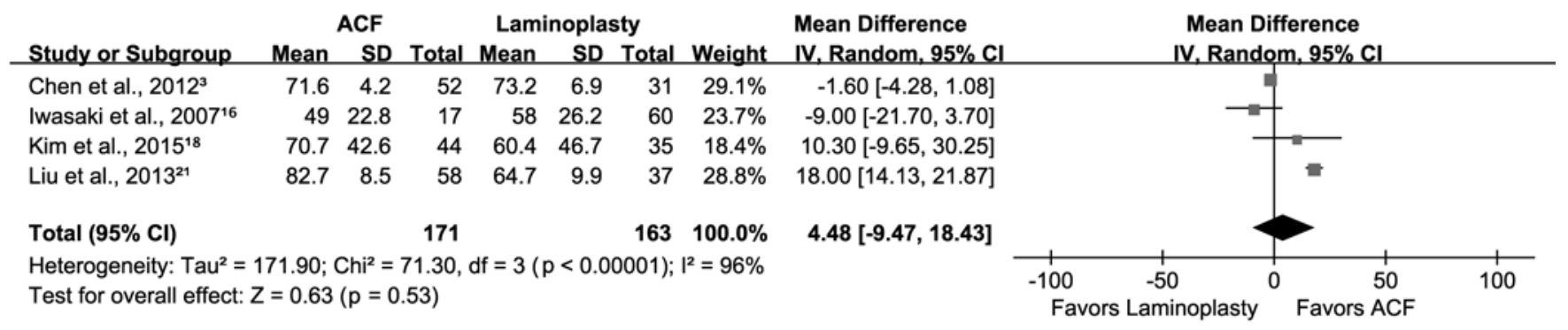

\begin{tabular}{|c|c|c|c|c|c|c|c|c|c|c|c|}
\hline \multirow[b]{2}{*}{ Study or Subgroup } & \multicolumn{3}{|c|}{ ACF } & \multicolumn{3}{|c|}{ Laminoplasty } & \multirow[b]{2}{*}{ Weight } & \multirow{2}{*}{$\begin{array}{l}\text { Mean Difference } \\
\text { IV, Random, } 95 \% \mathrm{Cl}\end{array}$} & \multirow{2}{*}{\multicolumn{3}{|c|}{$\begin{array}{c}\text { Mean Difference } \\
\text { IV, Random, } 95 \% \mathrm{Cl}\end{array}$}} \\
\hline & Mean & SD & Total & Mean & SD & Total & & & & & \\
\hline Chen et al., $2012^{3}$ & 64.1 & 3.2 & 52 & 42.5 & 5.8 & 31 & $40.2 \%$ & $21.60[19.38,23.82]$ & & 口 & \\
\hline Iwasaki et al., $2007^{16}$ & 58.3 & 17.2 & 17 & 14 & 35.9 & 60 & $17.2 \%$ & $44.30[32.08,56.52]$ & & & \\
\hline Kim et al., $2015^{18}$ & 75.7 & 30.3 & 44 & 41.7 & 84 & 35 & $4.5 \%$ & $34.00[4.77,63.23]$ & & & \\
\hline Liu et al., $2013^{21}$ & 68.6 & 7.8 & 58 & 42.3 & 8.2 & 37 & $38.1 \%$ & $26.30[22.98,29.62]$ & & = & \\
\hline Total $(95 \% \mathrm{Cl})$ & & & 171 & & & 163 & $100.0 \%$ & $27.85[21.27,34.44]$ & & & \\
\hline $\begin{array}{l}\text { Heterogeneity: } \mathrm{Tau}^{2}= \\
\text { Test for overall effect: }\end{array}$ & $\begin{array}{l}6.80 ; C \\
=8.29\end{array}$ & $\begin{array}{l}h i^{2}=1 \\
(p<0\end{array}$ & $\begin{array}{l}7.17, d t \\
.00001)\end{array}$ & $=3(p$ & $=0.00$ & $07) ; 1^{2}=$ & $=83 \%$ & & $\begin{array}{cc}-100 & -50 \\
\text { Favors Laminoplasty }\end{array}$ & $\begin{array}{l}0 \quad 50 \\
\text { Favors ACF }\end{array}$ & 100 \\
\hline
\end{tabular}

FIG. 5. Forest plot of recovery rate for the ACF group and the laminoplasty group according to the occupying ratio of OPLL. Upper: Occupying ratio $<60 \%$. Lower: Occupying ratio $\geq 60 \%$.

\section{Clinical Outcomes}

The preoperative JOA score played an important role in baseline evaluation. Since there was no significant difference in preoperative JOA score between the 2 groups, we can simply use postoperative JOA score as a parameter to compare the clinical outcomes. In our meta-analysis, both postoperative JOA score and recovery rate were higher in the ACF group, which meant that the ACF method could result in better neurological outcomes. The number of involved segments of OPLL was different between the surgical groups. Most surgeons tend to choose laminoplasty for patients with extensive levels of OPLL. Although statistical synthesis of the meta-analysis could not be conducted given the lack of sufficient data, we can expect the postoperative neurological recovery to be affected by the number of levels involved. To some extent, this may have contributed to the relatively poor clinical outcomes in the laminoplasty group. Clinical outcome was superior in the ACF group for patients with an occupying ratio $\geq 60 \%$. However, for patients with an occupying ratio $<60 \%$, the postoperative neurological recovery was similar for both groups. These results may be easily explained by the fact that $\mathrm{ACF}$ is a direct decompression method that removes the original compression of the spinal cord. Chen et al. ${ }^{4}$ completed a minimum 5-year follow-up after ACF treatment for patients with OPLL and reported satisfactory clinical outcomes in terms of postoperative JOA score, recovery rate, maintenance of cervical lordosis, and sagittal balance. Iwasaki et al. ${ }^{16}$ recommended ACF treatment for OPLL patients with an occupying ratio $\geq 60 \%$ and/or hill-shaped ossification, even though the ACF procedure is technically demanding and has a higher rate of surgeryrelated complications.

It is well known that laminoplasty is most often performed in patients who have adequate cervical lordosis. On occasion, it is also used for patients in whom the cervical spine was straightened or even kyphotic.,26 Ogawa et al. ${ }^{26}$ and Iwasaki et al. ${ }^{14}$ recommended expansive and extensive laminoplasty for the treatment of cervical OPLL, even in patients with mild kyphotic deformity. Their studies indicated that the long-term result after expansive laminoplasty was satisfactory. Our meta-analysis revealed that laminoplasty was performed less often in patients with kyphotic alignment (Table 3). This finding is explained by the fact that patients with cervical kyphosis who had undergone laminoplasty experienced significantly lower re-

TABLE 3. Results related to radiological assessment

\begin{tabular}{|c|c|c|c|c|c|c|c|}
\hline \multirow[b]{2}{*}{ Outcomes } & \multirow{2}{*}{$\begin{array}{l}\text { No. of } \\
\text { Studies }\end{array}$} & \multirow{2}{*}{$\begin{array}{c}\text { ACF } \\
\text { Sample No. }\end{array}$} & \multirow{2}{*}{$\begin{array}{c}\text { LAM }^{*} \\
\text { Sample No. }\end{array}$} & \multirow[b]{2}{*}{ WMD/OR (95\% Cl) } & \multirow[b]{2}{*}{$p$ Value $†$} & \multicolumn{2}{|c|}{ Heterogeneity Test } \\
\hline & & & & & & $1^{2}$ & $p$ Value \\
\hline Cases of preop kyphosis & 5 & 282 & 259 & $3.95(1.49-10.49)$ & 0.006 & $57 \%$ & 0.06 \\
\hline Cases of postop kyphosis & 4 & 139 & 179 & $0.20(0.09-0.42)$ & $<0.00001$ & $45 \%$ & 0.14 \\
\hline Postop lordotic angle & 2 & 44 & 54 & $6.12(5.50-6.75)$ & $<0.00001$ & $0 \%$ & 0.55 \\
\hline RR of kyphotic patients & 2 & 30 & 18 & $21.85(16.49-27.17)$ & $<0.00001$ & $0 \%$ & 0.40 \\
\hline RR of high cord signal on $\mathrm{T} 2 \mathrm{Wl}$ & 2 & 63 & 60 & $19.03(10.35-27.71)$ & $<0.0001$ & $0 \%$ & 0.78 \\
\hline
\end{tabular}




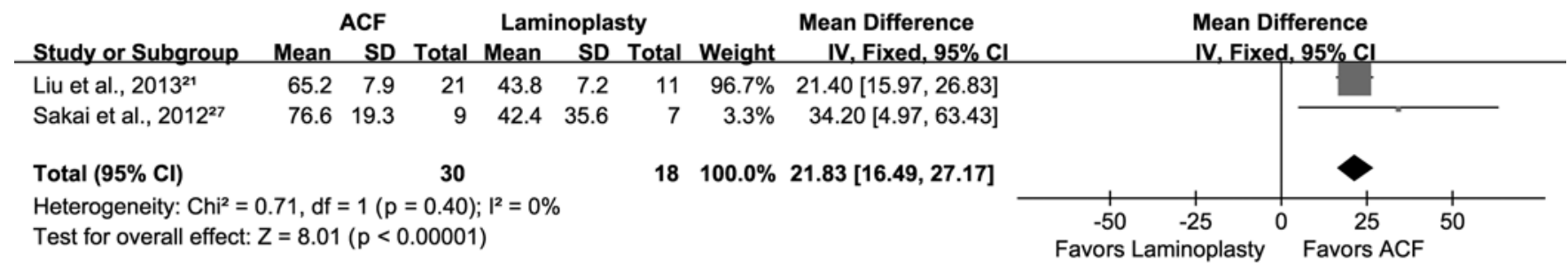

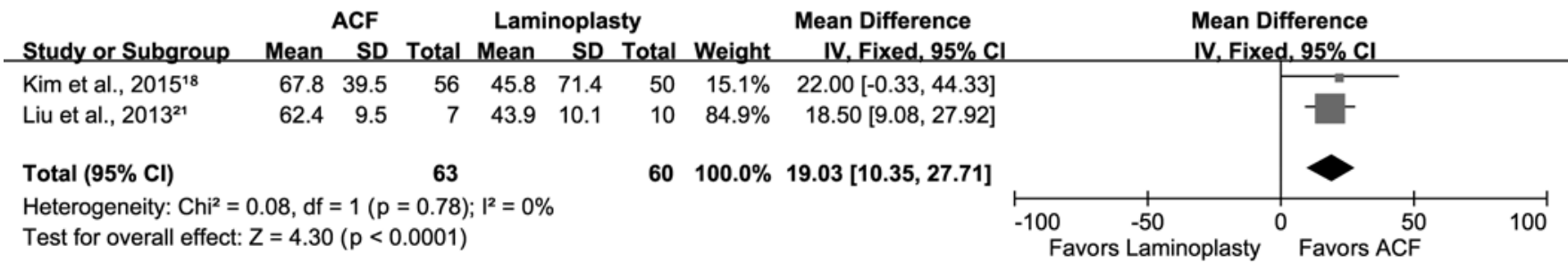

FIG. 6. Forest plot of recovery rate for the ACF group and the laminoplasty group in patients experiencing preoperative cervical kyphosis (upper) or high signal on T2-weighted MRI of the cervical spinal cord (lower).

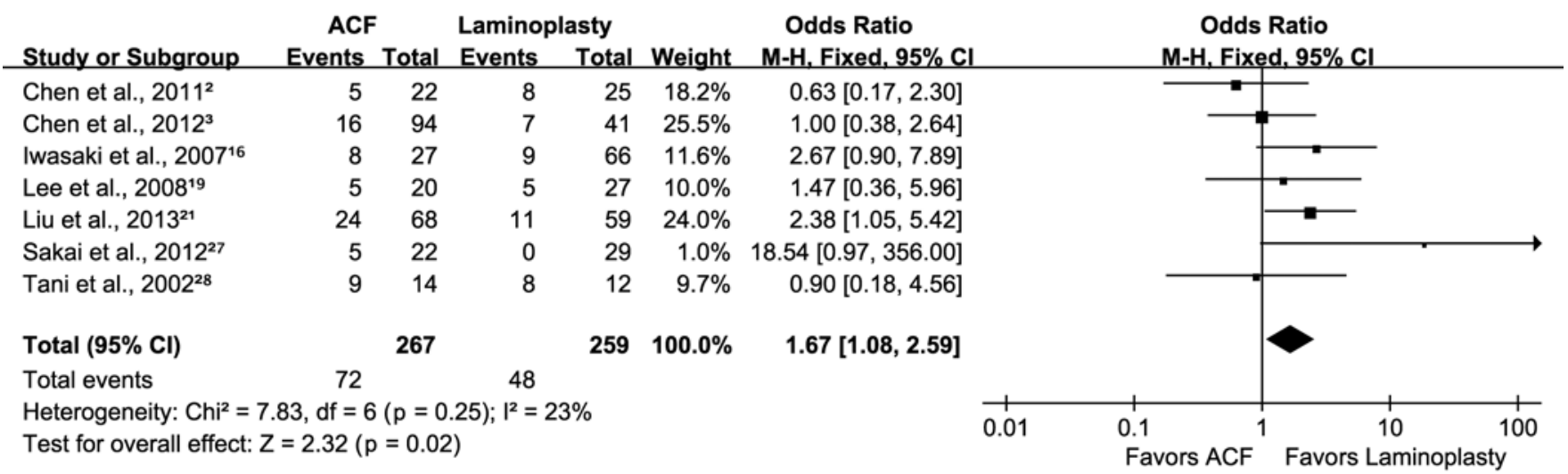

FIG. 7. Forest plot of complication rates in the ACF group and the laminoplasty group. $\mathrm{M}-\mathrm{H}=$ Mantel-Haenszel.

covery rates. Moreover, we found that the $\mathrm{C} 2-\mathrm{C} 7$ lordotic angle significantly decreased and that kyphotic deformity usually occurred after laminoplasty. The preparation and consecutive denervation of deep extensor muscles is a common cause of the loss of lordosis following laminoplasty. ${ }^{12}$ In long-term follow-ups, late neurological deterioration after laminoplasty was not rare and was attributable to the progression of OPLL and the occurrence of postoperative kyphosis. ${ }^{14,26,27}$

The presence of a high signal on T2-weighted MRI of the spinal cord was associated with poor outcomes even with adequate decompression. ${ }^{30}$ Early surgery was recommended for those patients to reduce further spinal cord injury. Based on our meta-analysis, a better recovery rate was observed after anterior surgery compared with posterior laminoplasty (Table 3). Hence, for patients with a high signal on T2-weighted MRI of the cervical spinal cord, $\mathrm{ACF}$ appears to be the preferable surgical method.

\section{Complications and Reoperations}

According to our meta-analysis (Table 4), ACF (24.85\%) has a higher complication rate than laminoplasty $(18.53 \%)$. Dysphagia and hoarseness, CSF leakage, and implant com-
TABLE 4. Number and percentage of complications

\begin{tabular}{|c|c|c|c|}
\hline \multirow[b]{2}{*}{ Parameter } & \multicolumn{2}{|c|}{ No. $(\%)$} & \multirow[b]{2}{*}{$p$ Value } \\
\hline & ACF Group & $\begin{array}{c}\text { Laminoplasty } \\
\text { Group }\end{array}$ & \\
\hline Total no. of patients & 338 & 259 & NA \\
\hline Dysphagia \& hoarseness & $29(8.58)$ & $0(0)$ & $0.006^{*}$ \\
\hline Implant complications & $14(4.14)$ & $0(0)$ & $0.03^{*}$ \\
\hline CSF leakage & $22(6.51)$ & $2(0.77)$ & $0.003^{*}$ \\
\hline Hematoma & $2(0.59)$ & $2(0.77)$ & 0.79 \\
\hline Axial pain & $0(0)$ & $15(5.79)$ & $0.009^{*}$ \\
\hline C-5 palsy & $5(1.48)$ & $18(6.95)$ & $0.002^{*}$ \\
\hline Neurological deterioration & $8(2.37)$ & $7(2.70)$ & 0.8 \\
\hline Wound infection & $0(0)$ & $0(0)$ & - \\
\hline Others & $4(1.18)$ & $4(1.54)$ & 0.19 \\
\hline Total & $84(24.85)$ & $48(18.53)$ & $0.02^{*}$ \\
\hline
\end{tabular}

* Statistically significant difference. 


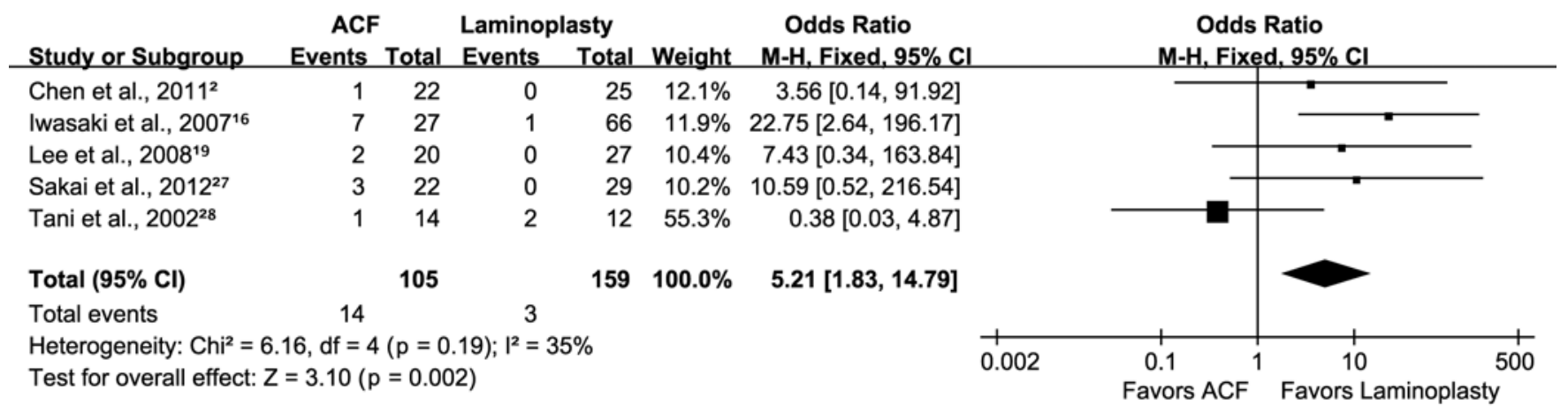

FIG. 8. Forest plot of reoperation rates for the ACF group and the laminoplasty group.

plications appeared more frequently in using the anterior approach, and these complications accounted for $8.58 \%$, $6.51 \%$, and $4.14 \%$ of the total detectable complications, respectively. The major complications associated with laminoplasty were $\mathrm{C}-5$ palsy (6.95\%) and axial pain (5.79\%). The incidences of specific complications in our meta-analysis were similar to those in a previous systematic review. $\mathrm{Li}$ et al. ${ }^{20}$ reported a total complication rate of $24.3 \%$ in using the anterior approach. They reported higher incidences of CSF leakage and implant complications, which accounted for $11.9 \%$ and $10.6 \%$ of the total detectable complications, respectively. However, hoarseness and dysphagia (5.6\%) were less often reported.

Many surgeons pay much attention to the occurrence of CSF leakage. The double-layer sign is a sensitive and valid indicator for diagnosing dural ossification, which is useful for indicating CSF leakage., ${ }^{6,31}$ CSF leakage can be easily and successfully managed using a combination of intraoperative adjuncts (fascial graft, gelatin sponge) and postoperative lumbar drainage..$^{17,24}$ For the ACF procedure, it was found that more complications occurred as the number of levels operated on increased. Increased levels of ACF were also associated with increased blood loss and operation time. ${ }^{4,16,18}$ Fraser and Härtl $^{7}$ conducted a meta-analysis to study the fusion rate of anterior cervical surgery. The fusion rate of 1-level ACF was $95.9 \%$, while the rate decreased to $89.8 \%$ in 2-level ACF; thus, the fusion rate decreased as the number of levels being fused increased. The above disadvantages could explain why laminoplasty rather than $\mathrm{ACF}$ was usually chosen for patients with extensive long-segment OPLL.

The prevalence of axial symptoms in $72(60 \%)$ patients after laminoplasty was reported by Hosono et al. ${ }^{10}$ In that study, $25 \%$ of patients suffered from axial pain for more than 3 months, and 13\% needed analgesics. The etiology of neck and shoulder pain after laminoplasty remains unclear, although it probably occurs secondary to posterior soft-tissue dissection and facet joint disruption. ${ }^{9}$ The symptom of C-5 palsy mainly presented as deltoid paralysis. C-5 palsy was supposed to be the result of a tethering effect on the nerve root near the apex of lordosis, which is induced by excessive shifting of the spinal cord after laminoplasty. Hence, avoiding cervical cord tethering by expansive laminoplasty may lower the incidence of C-5 palsy. Foraminotomy may be a useful treatment for patients with severe pain or motor paralysis. ${ }^{13,25}$

Data about reoperation for OPLL were limited. Our meta-analysis revealed a higher reoperation rate in the ACF group. The major reason for revision was implant complications (8 of 14 reoperations), such as bone graft dislocation and pseudarthrosis. Our results were similar to those in a systematic review conducted by Li and Dai, ${ }^{20}$ in

\begin{tabular}{|c|c|c|c|c|c|c|c|c|c|c|c|c|}
\hline Study or Subgroup & \multicolumn{3}{|c|}{ ACF } & \multicolumn{3}{|c|}{ Laminoplasty } & \multicolumn{2}{|c|}{$\begin{array}{ll} & \text { Mean Difference } \\
\text { Weight } & \text { IV, Random, } 95 \% \mathrm{Cl}\end{array}$} & \multicolumn{3}{|c|}{$\begin{array}{c}\text { Mean Difference } \\
\text { IV, Random, } 95 \% \mathrm{Cl}\end{array}$} & \\
\hline Iwasaki et al., $2007^{16}$ & 302 & 75.8 & 27 & 177 & 76.3 & 66 & $32.7 \%$ & $125.00[91.00,159.00]$ & & & - & \\
\hline Liu et al., $2013^{21}$ & 190 & 42.5 & 68 & 160 & 22.5 & 59 & $35.0 \%$ & $30.00[18.38,41.62]$ & & & $=$ & \\
\hline Sakai et al., $2012^{27}$ & 300.3 & 78.6 & 22 & 183.2 & 41.1 & 29 & $32.4 \%$ & $117.10[81.01,153.19]$ & & & $\longrightarrow$ & \\
\hline Total (95\% Cl) & & & 117 & & & 154 & $100.0 \%$ & $89.24[17.72,160.75]$ & & & & \\
\hline $\begin{array}{l}\text { Heterogeneity: } \mathrm{Tau}^{2}= \\
\text { Test for overall effect: }\end{array}$ & $\begin{array}{l}3774.14 \\
Z=2.45\end{array}$ & $\begin{array}{l}\mathrm{Chi}^{2} \\
(p=0\end{array}$ & $\begin{array}{l}=42.92 \\
.01)\end{array}$ & $\mathrm{df}=2($ & $p<0$. & $00001) ;$ & $; 1^{2}=95 \%$ & & -200 & $\begin{array}{l}-100 \quad 0 \\
\text { Favors ACF }\end{array}$ & $\begin{array}{c}100 \\
\text { Favors Lamino }\end{array}$ & $\begin{array}{l}200 \\
\text { pplasty }\end{array}$ \\
\hline
\end{tabular}

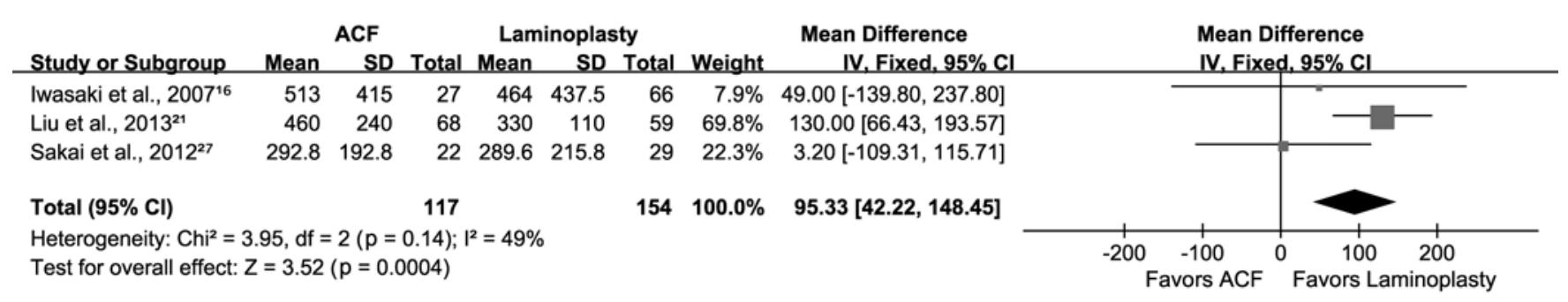

FIG. 9. Forest plot of operation time (upper) and blood loss (lower) in the ACF group and the laminoplasty group. 
which the authors reported that 12 of 26 cases with bone graft dislocation or fracture and all 9 cases of pseudarthrosis were managed with reoperation to attain solid fusion.

\section{Operation Time and Blood Loss}

According to our analysis, ACF was associated with a longer operation time and more intraoperative blood loss than laminoplasty. The surgical trauma was relatively large, and many older patients (over 65 years of age) could not tolerate anterior cervical surgery for OPLL. ${ }^{6}$

\section{Study Limitations}

Our meta-analysis has several limitations. First, all included studies were nonrandomized and their quality was not high. Although the quality seemed satisfactory according to the NOS assessment, we must acknowledge that further high-quality, randomized controlled trials with more patients should be performed. Second, the number of involved segments of OPLL was different between the surgical groups, which could impact clinical outcomes and affect decision making. Third, clinical heterogeneity exists because of the variety of surgical techniques used in each study. Fourth, the clinical results for different kinds of OPLL, such as the type (continuous, localized, or mixed) and shape (plateau- or hill-shaped), were lacking in our included studies. Furthermore, all included studies focused solely on the evaluation of neurological function improvement while neglecting to evaluate overall quality of life using instruments such as the SF-36 (36-Item Short Form Health Survey) or EQ-5D scale.

\section{Conclusions}

ACF produces a better neurological outcome for patients with cervical OPLL, especially those with an occupying ratio $\geq 60 \%$. However, attention should be paid to the higher incidence of complications and reoperations, longer operation time, and higher blood loss associated with ACF as compared with laminoplasty. We conclude that for patients with an occupying ratio $\geq 60 \%$ or with kyphotic cervical alignment, the ACF method appears to be preferable. Given that ACF has more complications and surgical trauma, laminoplasty seems to be effective and safe enough for patients with an occupying ratio $<60 \%$ or with adequate cervical lordosis. However, it must be emphasized that surgical strategy should be decided based on the individual patient's physical status, number of involved segments, and so on. Further randomized controlled trials comparing ACF with laminoplasty for patients with OPLL should be performed to arrive at a more convincing conclusion.

\section{References}

1. An HS, Al-Shihabi L, Kurd M: Surgical treatment for ossification of the posterior longitudinal ligament in the cervical spine. J Am Acad Orthop Surg 22:420-429, 2014

2. Chen Y, Guo Y, Lu X, Chen D, Song D, Shi J, et al: Surgical strategy for multilevel severe ossification of posterior longitudinal ligament in the cervical spine. J Spinal Disord Tech 24:24-30, 2011

3. Chen Y, Liu X, Chen D, Wang X, Yuan W: Surgical strategy for ossification of the posterior longitudinal ligament in the cervical spine. Orthopedics 35:e1231-e1237, 2012
4. Chen Y, Yang L, Liu Y, Yang H, Wang X, Chen D: Surgical results and prognostic factors of anterior cervical corpectomy and fusion for ossification of the posterior longitudinal ligament. PLoS One 9:e102008, 2014

5. Epstein N: Diagnosis and surgical management of cervical ossification of the posterior longitudinal ligament. Spine J 2:436-449, 2002

6. Epstein NE: Cervical surgery for ossification of the posterior longitudinal ligament: One spine surgeon's perspective. Surg Neurol Int 5 (Suppl 3):S88-S92, 2014

7. Fraser JF, Härtl R: Anterior approaches to fusion of the cervical spine: a metaanalysis of fusion rates. J Neurosurg Spine 6:298-303, 2007

8. Goto S, Kita T: Long-term follow-up evaluation of surgery for ossification of the posterior longitudinal ligament. Spine (Phila Pa 1976) 20:2247-2256, 1995

9. Hale JJ, Gruson KI, Spivak JM: Laminoplasty: a review of its role in compressive cervical myelopathy. Spine J 6 (6 Suppl):289S-298S, 2006

10. Hosono N, Yonenobu K, Ono K: Neck and shoulder pain after laminoplasty. A noticeable complication. Spine (Phila Pa 1976) 21:1969-1973, 1996

11. Hozo SP, Djulbegovic B, Hozo I: Estimating the mean and variance from the median, range, and the size of a sample. BMC Med Res Methodol 5:13, 2005

12. Iizuka H, Nakajima T, Iizuka Y, Sorimachi Y, Ara T, Nishinome M, et al: Cervical malalignment after laminoplasty: relationship to deep extensor musculature of the cervical spine and neurological outcome. J Neurosurg Spine 7:610-614, 2007

13. Imagama S, Matsuyama Y, Yukawa Y, Kawakami N, Kamiya M, Kanemura T, et al: C5 palsy after cervical laminoplasty: a multicentre study. J Bone Joint Surg Br 92:393-400, 2010

14. Iwasaki M, Kawaguchi Y, Kimura T, Yonenobu K: Longterm results of expansive laminoplasty for ossification of the posterior longitudinal ligament of the cervical spine: more than 10 years follow up. J Neurosurg 96 (2 Suppl):180-189, 2002

15. Iwasaki M, Okuda S, Miyauchi A, Sakaura H, Mukai Y, Yonenobu K, et al: Surgical strategy for cervical myelopathy due to ossification of the posterior longitudinal ligament: Part 1: Clinical results and limitations of laminoplasty. Spine (Phila Pa 1976) 32:647-653, 2007

16. Iwasaki M, Okuda S, Miyauchi A, Sakaura H, Mukai Y, Yonenobu K, et al: Surgical strategy for cervical myelopathy due to ossification of the posterior longitudinal ligament: Part 2: Advantages of anterior decompression and fusion over laminoplasty. Spine (Phila Pa 1976) 32:654-660, 2007

17. Joseph V, Kumar GS, Rajshekhar V: Cerebrospinal fluid leak during cervical corpectomy for ossified posterior longitudinal ligament: incidence, management, and outcome. Spine (Phila Pa 1976) 34:491-494, 2009

18. Kim B, Yoon H, Shin HC, Kim KN, Yi S, Shin DA, et al: Surgical outcome and prognostic factors of anterior decompression and fusion for cervical compressive myelopathy due to ossification of the posterior longitudinal ligament. Spine $\mathbf{J}$ 15:875-884, 2015

19. Lee SH, Ahn Y, Lee JH: Laser-assisted anterior cervical corpectomy versus posterior laminoplasty for cervical myelopathic patients with multilevel ossification of the posterior longitudinal ligament. Photomed Laser Surg 26:119-127, 2008

20. Li H, Dai LY: A systematic review of complications in cervical spine surgery for ossification of the posterior longitudinal ligament. Spine J 11:1049-1057, 2011

21. Liu H, Li Y, Chen Y, Wu W, Zou D: Cervical curvature, spinal cord MRIT2 signal, and occupying ratio impact surgical approach selection in patients with ossification of the posterior longitudinal ligament. Eur Spine J 22:1480-1488, 2013 
22. Masaki Y, Yamazaki M, Okawa A, Aramomi M, Hashimoto M, Koda M, et al: An analysis of factors causing poor surgical outcome in patients with cervical myelopathy due to ossification of the posterior longitudinal ligament: anterior decompression with spinal fusion versus laminoplasty. J Spinal Disord Tech 20:7-13, 2007

23. Matsunaga S, Sakou T: Ossification of the posterior longitudinal ligament of the cervical spine: etiology and natural history. Spine (Phila Pa 1976) 37:E309-E314, 2012

24. Mazur M, Jost GF, Schmidt MH, Bisson EF: Management of cerebrospinal fluid leaks after anterior decompression for ossification of the posterior longitudinal ligament: a review of the literature. Neurosurg Focus 30(3):E13, 2011

25. Minoda Y, Nakamura H, Konishi S, Nagayama R, Suzuki E, Yamano Y, et al: Palsy of the C5 nerve root after midsagittalsplitting laminoplasty of the cervical spine. Spine (Phila Pa 1976) 28:1123-1127, 2003

26. Ogawa Y, Toyama Y, Chiba K, Matsumoto M, Nakamura M, Takaishi H, et al: Long-term results of expansive open-door laminoplasty for ossification of the posterior longitudinal ligament of the cervical spine. J Neurosurg Spine 1:168174,2004

27. Sakai K, Okawa A, Takahashi M, Arai Y, Kawabata S, Enomoto M, et al: Five-year follow-up evaluation of surgical treatment for cervical myelopathy caused by ossification of the posterior longitudinal ligament: a prospective comparative study of anterior decompression and fusion with floating method versus laminoplasty. Spine (Phila Pa 1976) 37:367376,2012

28. Tani T, Ushida T, Ishida K, Iai H, Noguchi T, Yamamoto H: Relative safety of anterior microsurgical decompression versus laminoplasty for cervical myelopathy with a massive ossified posterior longitudinal ligament. Spine (Phila Pa 1976) 27:2491-2498, 2002

29. Wells G, Shea B, O'Connell D, Peterson J, Welch V, Losos M, et al: The Newcastle-Ottawa Scale (NOS) for assessing the quality of nonrandomised studies in meta-analyses. Ottawa Hospital Research Institute. (http://www.ohri.ca/programs/ clinical_epidemiology/oxford.asp) [Accessed April 5, 2016]

30. Yagi M, Ninomiya K, Kihara M, Horiuchi Y: Long-term surgical outcome and risk factors in patients with cervical myelopathy and a change in signal intensity of intramedullary spinal cord on magnetic resonance imaging. J Neurosurg Spine 12:59-65, 2010

31. Yang H, Yang L, Chen D, Wang X, Lu X, Yuan W: Implications of different patterns of "double-layer sign" in cervical ossification of the posterior longitudinal ligament. Eur Spine J 24:1631-1639, 2015

\section{Disclosures}

The authors report no conflict of interest concerning the materials or methods used in this study or the findings specified in this paper.

\section{Author Contributions}

Conception and design: Rong, Z Chen, Liu. Acquisition of data: Z Chen, Feng, R Chen, Xie. Analysis and interpretation of data: Z Chen, Feng, R Chen, Xie. Drafting the article: Z Chen, Liu, Dong. Critically revising the article: Rong, Z Chen, Liu, Dong. Reviewed submitted version of manuscript: Rong, Z Chen, Liu, Dong, Zhang. Approved the final version of the manuscript on behalf of all authors: Rong. Statistical analysis: Z Chen, Feng, R Chen, Xie, Zhang. Administrative/technical/material support: Rong. Study supervision: Rong.

\section{Correspondence}

Limin Rong, Department of Spine Surgery, The Third Affiliated Hospital of Sun Yat-sen University, No. 600 Tianhe Rd., Guangzhou 510630, China. email: drronglimin@21cn.com. 